\title{
Anti-glomerular basement membrane disease case series in Trinidad and Tobago
}

\author{
E Mohammed ${ }^{1}$, A Ramrattan ${ }^{2 *}$, R Poon-King 3 , A Bissessar ${ }^{4}$, A Ramesar ${ }^{4}$, S Giddings $^{5}$ and AVC Rao ${ }^{6}$ \\ ${ }^{1}$ Department of Internal Medicine, Northwest Regional Health Authority, Port-of-Spain General Hospital and University of the West Indies, St Augustine, \\ Trinidad and Tobago \\ ${ }^{2}$ Deparment of Internal Medicine, Northwest Regional Health Authority, Port-of-Spain General Hospital, Trinidad and Tobago \\ ${ }^{3}$ St. Augustine Private Hospital, St. Augustine, Trinidad and Tobago \\ 4Department of Internal Medicine, Southwest Regional Health Authority, San Fernando General Hospital \\ ${ }^{5}$ Department of Internal Medicine, Southwest Regional Health Authority, San Fernando General Hospital and University of the West Indies, St Augustine, \\ Trinidad and Tobago \\ ${ }^{6}$ Department of Pathology, St. Augustine, University of the West Indies, Trinidad and Tobago
}

\begin{abstract}
Goodpasture's syndrome (GS) or Anti-glomerular basement membrane disease (Anti-GBM) is a rapidly progressive glomerulonephritis (RPGN) with or without pulmonary hemorrhage characterized as a type 2 hypersensitivity reaction against type 4 collagen in the basement membrane. It presents more commonly in the white and Asian population and is exceedingly rare in the African population. The incidence of Anti-GBM disease is reported at 0.5-1.8 cases per million per year in both European white and Asian populations [1], with no known incidences in the English-speaking Caribbean population. We present three cases of the rare Anti-GBM disease in Trinidad and Tobago over the course of one calendar year.
\end{abstract}

\section{Case 1}

A 67-year-old female of East Indian ethnicity, with a past history of rheumatic fever in childhood and a one-month history of hypertension, presented with orthopnea, paroxysmal nocturnal dyspnea and leg edema for 4 days, with decreasing urine output for 2 days. At the time of presentation medications were Losartan and Furosemide. She was a non-smoker. Positive findings on examination revealed an obese lady with a weight $85.9 \mathrm{~kg}$ and BMI of 32, pallor and she had clinical evidence of pulmonary edema. Urinalysis showed 4+ protein and 4+blood. Her admitting bloods showed a blood urea nitrogen (BUN) of $113 \mathrm{mg} / \mathrm{dl}$, Creatinine of $13.8 \mathrm{mg} / \mathrm{dl}$, Potassium $\left(\mathrm{K}^{+} 7.3 \mathrm{mEq} / \mathrm{L}\right.$, Hemoglobin $7.6 \mathrm{~g} /$ $\mathrm{dl}$, white blood cell count $10 \mathrm{k} / \mu \mathrm{l}$ and platelet $372 \mathrm{k} / \mu \mathrm{l}$. HIV rapid test/ Hepatitis $\mathrm{B} / \mathrm{C}$ and ANA negative. KUB Ultrasound showed normal size kidneys $9.4 \mathrm{~cm}$ on the right and $9.8 \mathrm{~cm}$ left with increased echogenicity. Echocardiogram showed diastolic dysfunction and Chest X-ray was in keeping with pulmonary congestion.

This patient with acute kidney injury was diagnosed with a likely primary glomerulonephritis and she was commenced on acute hemodialysis. During investigative work-up, her p-ANCA and c-ANCA were negative but anti-GBM antibody was > $100 \mathrm{U} / \mathrm{ml}$, supporting the diagnosis of anti-GBM disease. Patient was converted to Peritoneal Dialysis (PD) and anti-hypertensives changed to amlodipine, hydralazine and alpha-methyldopa. Patient remained PD for three years prior to her demise. During her disease course, there was no episodes of pulmonary hemorrhage.

\section{Case 2}

This 39-year-old female patient, mixed-Caucasian ethnicity, was admitted with a three-day history of vomiting, dysuria, and hematuria.
There was no history of prior medical co-morbidities. Admission bloods showed a White blood cell count of $18 \mathrm{k} / \mu \mathrm{l}$, Hemoglobin of $9 \mathrm{~g} /$ $\mathrm{dl}$ with Mean corpuscular volume (MCV) of 78 . Admitting Creatinine was $1.7 \mathrm{mg} / \mathrm{dl}$ and admitting Urinalysis showed 3+ blood and $1+$ protein. She was assessed as an acute pyelonephritis with microcytic anemia and acute kidney injury at the time of admission. Her renal function rapidly declined which necessitated acute dialysis. Further investigations showed the following: KUB USS: Right kidney 13.4X5.8 $\mathrm{cm}$ and left kidney $11.4 \mathrm{X} 6 \mathrm{~cm}$ in sizes. Urine culture and sensitivity (MCS) grew E-coli and Candida sensitive to amoxicillin/clavulanic acid and ciprofloxacin. ASOT titers and leptospirosis titers were negative as well as HIV testing. 24-hour urine protein had $2307 \mathrm{mg}$ protein in 24 hours. ANA. $p$ and c ANCA, DCT/IDCT were all negative. Ds-DNA positive, anti-histone/SSB positive, Anti GBM antibodies: 423.67 (elevated).

This patient went on to have a renal biopsy which showed chronic glomerulonephritis resulting from advanced Anti GBM Ab disease. Patient was pulsed with Methylprednisolone and then started on tapering dose of prednisolone. There was no cyclophosphamide in hospital at the time and at one-year follow up, the patient was stable on hemodialysis.

${ }^{*}$ Correspondence to: Amit Ramrattan, Deparment of Internal Medicine, Northwest Regional Health Authority, Port-of-Spain General Hospital, Trinidad and Tobago, E-mail: amitramrattan400@gmail.com

Key words: Anti-GBM disease

Received: January 18, 2021; Accepted: January 26, 2021; Published: January 29, 2021 


\section{Case 3}

A 71-year-old female Trinbagonian of Caucasian descent with a past medical history of Hypertension and ex-smoker of 4 years and previously well presented with a two-week history of generalized malaise, headache, joint pain, nausea and dyspeptic symptoms and brown urine. Her admitting bloods showed a Hemoglobin (Hb) of $8 \mathrm{~g} /$ $\mathrm{dl}$, white blood cell (WCC) $11.1 \mathrm{k} / \mu \mathrm{l}$, platelet (Plt) $334 \mathrm{k} / \mu \mathrm{l}$ and a blood urea nitrogen (BUN) $68 \mathrm{mg} / \mathrm{dl}$ and Creatinine $(\mathrm{Cr}) 8.3 \mathrm{mg} / \mathrm{dl}$ and an erythrocyte sediment rate (ESR) 147. Admitting Urinalysis showed 3+ proteinuria with active urine sediment with red cells, red cell casts and leukocyturia.

This patient with acute kidney injury (AKI) was diagnosed as having primary glomerulonephritis versus an autoimmune cause was started on hemodialysis during which further blood investigation showed HIV negative, hepatitis $\mathrm{B}$ and $\mathrm{C}$ negative, p-ANCA and c-ANCA negative, anti-streptolysin $\mathrm{O}$ titres negative, negative serum protein electrophoresis with immunofixation. Renal ultrasound showed increased echogenicity of the renal parenchyma, with normal sized kidneys and no hydronephrosis.

Methylprednisolone $500 \mathrm{mg}$ was then commenced for 3 days followed by oral prednisolone $40 \mathrm{mg}$ daily with proton-pump inhibitor coverage. A kidney biopsy was then arranged with showed severe acute diffuse crescentic glomerulonephritis with acute tubular injury, tubular atrophy and interstitial fibrosis and Immunofluorescence findings of $3+$ linear staining for IgG along the basement membrane with $2+$ lambda and kappa and $1+\mathrm{C} 3$ supported a diagnosis of anti-GlomeruloBasement antibody (anti-GBM) nephritis. Subsequent anti-GBM titres were strongly positive.

Cyclophosphamide at $1 \mathrm{mg} / \mathrm{kg} /$ day was then instituted but one week on therapy, the patient presented with new onset generalized tonic-clonic seizures, headaches, delirium and blurry vision. CT- brain showed areas of decreased attenuation are noted in both occipital lobes consistent with Posterior reversible encephalopathy syndrome.

Cyclophosphamide was discontinued and patient had started to improve neurologically. Negative blood and urine cultures made sepsis an unlikely contributing factor and normal liver enzymes meant a metabolic encephalopathy was unlikely as well. The patient rapidly developed hypoxic episodes followed by a respiratory arrest due to fulminant pulmonary hemorrhage before plasmapheresis can be commenced.

\section{Discussion}

Goodpasture's syndrome (GPS) is a type 2 hypersensitivity reaction against the $\mathrm{NC} 1$ epitope of the alpha- 3 chain of type 4 collagen leading to rapidly progressive glomerulonephritis and alveolar hemorrhage if not treated promptly with immunosuppressive therapy or plasmapheresis [2]. Its etiology is largely linked to the release of this antigenic molecule following pulmonary vascular insults especially from hydrocarbons, smoking as with case 3 , infection such as influenza and cocaine inhalation. Its incidence is estimated $0.5-1.8$ cases per million population and is recognized in European and other white populations and in Asian populations and is rare in African populations. This corelates with our three cases whereby two of whom were of Caucasian background, highlighting the fact that this disease is almost never seen in our given population dominated by those of African and East Indian decent. Anti-GBM disease has a bimodal distribution from 20-30 years with a high male preponderance and presenting with pulmonary hemorrhage and then 60-70 years with a high female preponderance with renal failure as the main presentation. There are variations to the presentation of this disease with $60-80 \%$ having both pulmonary and renal involvement, $20-40 \%$ having renal involvement only and less than $10 \%$ with pulmonary involvement only [3].

This case series highlights three patients with Anti-GBM disease, all whose antibody titers were positive, of which two had renal biopsy proven disease. These patients remained dialysis dependent with a mortality of $33.3 \%$ at 3 months and $66.7 \%$ at 3 years. Anti-GBM disease, therefore, carries a high morbidity and mortality in our population. Only one patient developed pulmonary hemorrhage and this patient's history was positive for cigarette smoking.

Given the rarity of Anti-GBM disease combined with the expense of anti-GBM titers, it is not routinely screened for in Trinidad and Tobago. Since the advent of the National Renal histopathology meetings, the incidence of such rare diseases has become apparent. These cases, all from 2016-2017, suggest that the incidence of Anti-GBM disease could be as high as 2.1 cases per million. These cases also highlight the limited availability of timely treatments such as plasmapheresis and in one case, the cytotoxic agent, cyclophosphamide [4-7].

\section{Conclusion}

Anti-GBM disease, though rare, does exist in Trinidad and Tobago and may even have a higher incidence than is reported in the literature. Physicians must be acutely aware of the possibility of this diagnosis in AKI. Additionally, other uncommon renal conditions such as Hemolytic uremic syndrome and recurrence of glomerular disease in kidney transplants have occurred with disappointing outcomes due to lack of plasmapheresis. This case series reinforces the need for a National plasmapheresis service in Trinidad and Tobago.

\section{References}

1. Tang W, McDonald SP, Hawley CM, Badve SV, Boudville NC, et al. (2013) Antiglomerular basement membrane antibody disease is an uncommon cause of end-stage renal disease. Kidney Int 83: 503-510. [Crossref]

2. Hellmark T, Segelmark M (2014) Diagnosis and classification of Goodpasture's disease (anti-GBM). J Autoimmun 48-49: 108-112. [Crossref]

3. Jayaweera JL, Withana MR, Dalpatadu CKP, Beligaswatta CD, Rajapakse T, et al (2014) Cyclophosphamide-induced posterior reversible encephalopathy syndrome (PRES): A case report. J Med Case Rep 8: 442.

4. Shiferawa B, Miroa V, Smitha C, Akellaa J, Chuaa W, et al. (2016) Goodpasture's disease: An uncommon disease with an atypical clinical course. J Clin Med Res 8: 52-55. [Crossref]

5. Scailteux L-M, Hudier L, Renaudineau E, Jego P, Drouet T (2015) Posterior reversible encephalopathy syndrome after a first injection of cyclophosphamide: A case report. J Pharmacovigilance 3: 3 .

6. Hudson BG (2004) The molecular basis of goodpasture and alport syndromes: Beacons for the discovery of the collagen IV family. J Am Soc Nephrol 15: 2514-2527. [Crossref]

7. Preul C, Gerth J, Lang S, Bergmeier C, Witte OW, et al. (2009) Cerebral involvement in a patient with Goodpasture's disease due to shortened induction therapy: a case report. J Med Case Rep 3: 120. [Crossref]

Copyright: (C2021 Mohammed E. This is an open-access article distributed under the terms of the Creative Commons Attribution License, which permits unrestricted use, distribution, and reproduction in any medium, provided the original author and source are credited. 